\title{
An Ecological Assessment of the Panama Lagoon Complex, Eastern Province, Sri Lanka
}

\author{
Perera P.K.P. ${ }^{1^{*}}$ and Kariyawasam I.U. ${ }^{2}$ \\ ${ }^{I}$ Department of Forestry and Environmental Science, University of Sri Jayewardenepura, Sri Lanka \\ ${ }^{2}$ Department of Botany, University of Sri Jayewardenepura, Sri Lanka \\ *priyan@sjp.ac.lk
}

\begin{abstract}
The Panama lagoon is located in, Ampara District, on the Eastern coast of Sri Lanka. This relatively small brackish water lagoon spans over an area of less than $1.5 \mathrm{~km}^{2}$, but encompasses variety of habitat types ranging from natural and semi-natural habitats to modified habitats by humans, thus performing an important ecological role. Biogeographically, Panama lagoon area falls under floristic regions I and II i.e. Coastal and Marine Belt and Dry and Arid Lowlands. It further belongs to the bioclimatic region B: Dry Zone.
\end{abstract}

Field investigations carried out during the period of August to December, 2015 identified 11 major natural and man-made habitat types, including terrestrial, aquatic and semi-aquatic systems. Natural terrestrial habitats included scrublands, dry mixed evergreen forests, rock outcrop vegetation, and sand dunes. Anthropogenic terrestrial habitats were predominantly represented by chena/crop cultivations and home gardens. Natural wetland habitats included sea shore vegetation, salt marsh, mangrove and lagoon, while paddy fields represented anthropogenic wetland habitats.

The plant species recorded included 41 trees, 47 shrubs, 92 herbs, 25 climbers including lianas and epiphytes. Recorded flowering plants included 160 native species (77\%) with 2 endemic species (1\%). Due to the high human influences on the environment, numerous alien species were found in the terrestrial habitats of the lagoon. There were 43 introduced species (exotics) (20.6\%) recorded. Introduced species included 3 invasive alien species and 27 naturalized exotics. Seven $(3.36 \%)$ nationally threatened plant species were recorded from the area. It includes 4 Nationally Endangered (EN) and 3 Nationally Vulnerable (VU) species. The study site also has 19 Nationally Near-Threatened (NT) species. Rapid faunal assessment undertaken to cover all habitat types in and around the lagoon recorded a total of 242 faunal species. This included 23 mammals, 128 birds, 25 reptiles, 7 amphibians, 35 butterfly species and 23 dragonfly species. Out of the total 242 faunal species recorded, 214 were native to the country $(88.4 \%)$ while 7 species are listed as endemic (2.9\%). There were 14 nationally threatened faunal species recorded in the study area which included 4 mammals, 6 birds, and 4 insect species (butterflies and dragonflies). A considerable area of the lagoon complex has been already subjected to human influences such as agriculture and residential developments, causing substantial threats to lagoon ecological resources. As Panama lagoon is a rich repository of native biodiversity, and an important habitat for migrant birds, it is imperative that the entire system is sustainably managed to achieve a balance between conservation and utilization.

Keywords: Panama lagoon, Biodiversity, Dry zone, Floral diversity, Faunal diversity

Proceedings of the International Forestry and Environment Symposium 2016, Department of Forestry and Environmental Science, University of Sri Jayewardenepura, Sri Lanka. 